\title{
Perimesencephalic hemorrhage with negative angiography: case illustration
}

\author{
Peter F. Morgenstern, MD, and Jared Knopman, MD \\ Department of Neurological Surgery, NewYork-Presbyterian Hospital/Weill Cornell Medical Center, New York, \\ New York
}

http://thejns.org/doi/abs/10.3171/2014.12.JNS142513

KEY WORDS perimesencephalic hemorrhage; aneurysm; angiogram-negative subarachnoid hemorrhage; vascular disorders

\begin{abstract}
A 44-year-old woman presented with headache and perimesencephalic subarachnoid hemorrhage (PM-SAH). Initial digital subtraction angiography (DSA) and CT angiography (CTA) showed no underlying pathology (Fig. 1A). On Day 9 DSA revealed a 1.7mm aneurysm of the basilar trunk (Fig. 1B), but CTA on Day 14 failed to demonstrate this aneurysm. The aneurysm was clipped via a subtemporal craniotomy. Postoperative DSA confirmed no residual filling (Fig. 1C), and the patient recovered well.

PM-SAH portends a better prognosis and lower probability of aneurysmal pathology and recurrent hemorrhage than aneurysmal SAH. Aneurysms can be found in PM-SAH but are typically identified on initial DSA or CTA. ${ }^{1}$ Some argue that a single angiographic evaluation is sufficient in patients with PM-SAH. Small aneurysms are found in few patients and disappear
\end{abstract}

on follow-up studies, ${ }^{5}$ suggesting that identification of the aneurysm may not confer a benefit. This information and concurrent improvements in the sensitivity of CTA have prompted some to consider replacing DSA with CTA in cases of PM-SAH and eliminating repeat studies. ${ }^{3}$ Advocates of this approach cite unnecessary risks of DSA and radiation exposure in the setting of a "benign" hemorrhage pattern.

This case illustrates that a negative DS angiogram does not definitively exclude aneurysmal etiology in PM-SAH. Furthermore, we recommend a conservative approach, utilizing rotational 3D DSA on initial and repeat studies to identify small intracranial aneurysms. This modality remains slightly more sensitive than CTA and conventional DSA at this time., ${ }^{2,4}$ Prospective studies are needed to ascertain whether detection and treatment of these aneurysms confer a benefit.

SUBMITTED November 4, 2014. ACCEPTED December 9, 2014. 

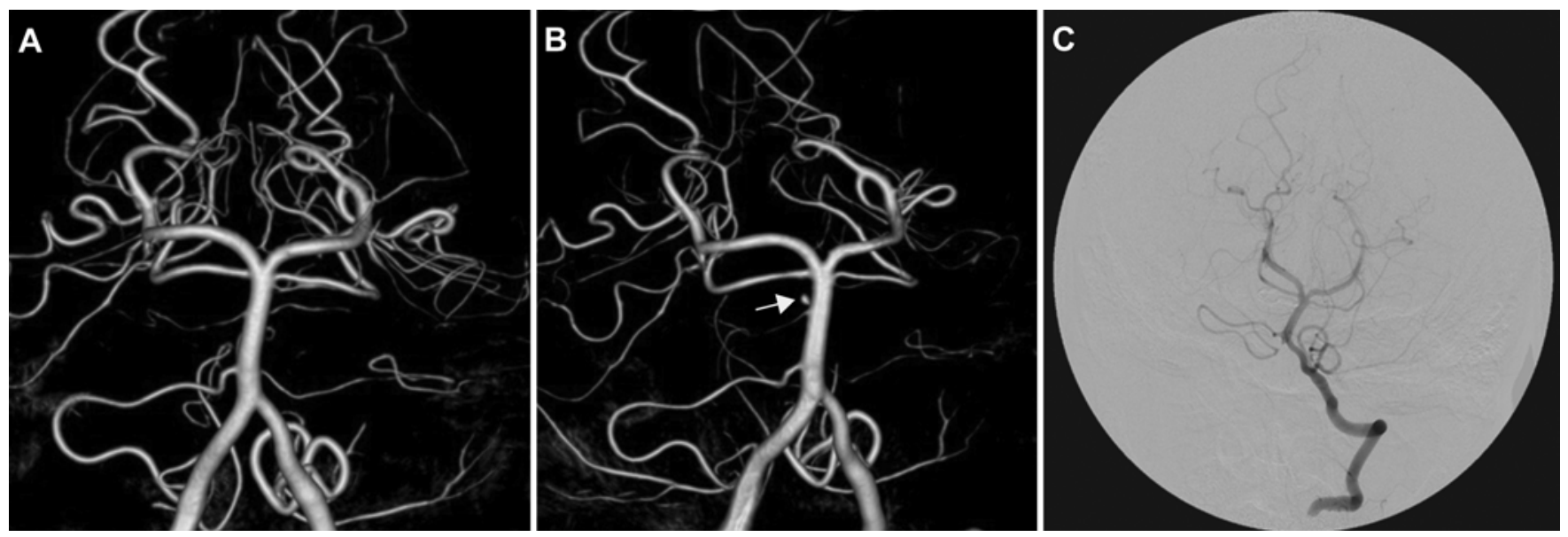

FIG. 1. A: DS angiogram on admission fails to demonstrate an etiology of SAH. B: Repeat DS angiogram on hospital Day 9 demonstrates a 1.7-mm aneurysm distal to the origin of the anterior inferior cerebellar artery (arrow). C: Postoperative DS angiogram demonstrates no residual filling of the aneurysm.

\section{References}

1. Alén JF, Lagares A, Lobato RD, Gómez PA, Rivas JJ, Ramos A: Comparison between perimesencephalic nonaneurysmal subarachnoid hemorrhage and subarachnoid hemorrhage caused by posterior circulation aneurysms. J Neurosurg 98:529-535, 2003

2. Kayhan A, Koc O, Keskin S, Keskin F: The role of bone subtraction computed tomographic angiography in determining intracranial aneurysms in non-traumatic subarachnoid hemorrhage. Iran J Radiol 11:e12670, 2014

3. Li K, Wei X, Lv F, Li Q, Xie P: Subarachnoid hemorrhage: role of subtraction CT angiography in etiological diagnosis and pretreatment planning. J Neurosurg Sci 58:223-229, 2014

4. Li Q, Lv F, Yao G, Li Y, Xie P: 64-section multidetector $\mathrm{CT}$ angiography for evaluation of intra- cranial aneurysms: comparison with 3D rotational angiography. Acta Radiol 55:840-846, 2014

5. Nayak S, Kunz AB, Kieslinger K, Ladurner $\mathrm{G}$, Killer M: Classification of non-aneurysmal subarachnoid haemorrhage: CT correlation to the clinical outcome. Clin Radiol 65:623-628, 2010

\section{Author Contributions}

Conception and design: both authors. Acquisition of data: Morgenstern. Analysis and interpretation of data: Morgenstern. Drafting the article: Morgenstern. Critically revising the article: both authors. Reviewed submitted version of manuscript: both authors. Approved the final version of the manuscript on behalf of both authors: Morgenstern. Study supervision: Knopman. 